Article

\title{
Optimal Scheduling for the Complementary Energy Storage System Operation Based on Smart Metering Data in the DC Distribution System
}

\author{
Bokyung Ko ${ }^{1}$, Nugroho Prananto Utomo ${ }^{1}$, Gilsoo Jang ${ }^{1, *}$, Jaehan Kim ${ }^{2}$ and Jintae Cho ${ }^{2}$ \\ 1 School of Electrical Engineering, Korea University, Seoul 136-713, Korea; \\ E-Mails: ok66551st@korea.ac.kr (B.K.); prana@korea.ac.kr (N.P.U.) \\ 2 Korea Electric Power Research Institute (KEPRI), Daejeon 305-760, Korea; \\ E-Mails: jhkim79@kepco.co.kr (J.K.); jintaecho@kepco.co.kr (J.C.) \\ * Author to whom correspondence should be addressed; E-Mail: gjang@korea.ac.kr; \\ Tel.: +82-2-3290-3246; Fax: +82-2-3290-3692.
}

Received: 16 October 2013; in revised form: 11 December 2013 / Accepted: 12 December 2013 / Published: 18 December 2013

\begin{abstract}
The increasing penetration of distributed generation (DG) sources in low-voltage grid feeders causes problems concerning voltage regulation. The penetration of DG sources such as photovoltaics (PVs) in the distribution system can significantly impact the power flow and voltage conditions on the customer side. As the DG sources are more commonly connected to low-voltage distribution systems, voltage fluctuations in the distribution system are experienced because of the DG fluctuation and uncertainty. Therefore, the penetration of DGs in distribution systems is often limited by the required operating voltage ranges. By using an energy storage system (ESS), voltage fluctuation can be compensated for, thus satisfying the voltage regulation requirements. This paper presents an ESS scheduling algorithm based on the power injection data obtained from a smart metering system. The proposed ESS scheduling algorithm is designed for use within a direct current (DC) distribution grid, which comprises customers, each with a PV and an ESS system. The purpose of this ESS scheduling algorithm is to optimize the ESS scheduling by considering the complementary operation among all the ESSs.
\end{abstract}

Keywords: energy storage system (ESS); ESS scheduling; distributed generation (DG); power flow; DC power flow; decoupled power flow 


\section{Introduction}

Various renewable energy generation methods have been developed to reduce greenhouse gas emissions. As renewable energy generation, which is susceptible to changes in the weather and environmental conditions, is expected to be increasingly connected to distribution systems in the future, voltage regulation problems in the distribution systems are receiving increased attention. High penetration of renewable energy generation in a distribution system can cause voltage problems because of the fluctuation in the active power injection [1].

In the Korea Electric Power Corporation (KEPCO) system, the photovoltaic (PV)-concentrated areas in low-voltage distribution systems, such as the Cheon-an distribution system, generally experience overvoltage problems. This suburban area has 36 houses, each with $2.5 \mathrm{~kW}$ of PV panels on one phase (A phase). During high insolation periods, excessive power from the PVs flows along each branch; this reverse power flow causes a voltage rise. As shown in Figure 1, the A phase voltage in this KEPCO distribution system experiences a higher voltage when compared with the other phases during periods of high PV generation, therefore, the PV penetration must be limited in order to maintain a reliable distribution system voltage.

Figure 1. Voltage profile, including photovoltaic (PV) generation, within KEPCO's low-voltage distribution system during a day (A phase connected with many PVs).

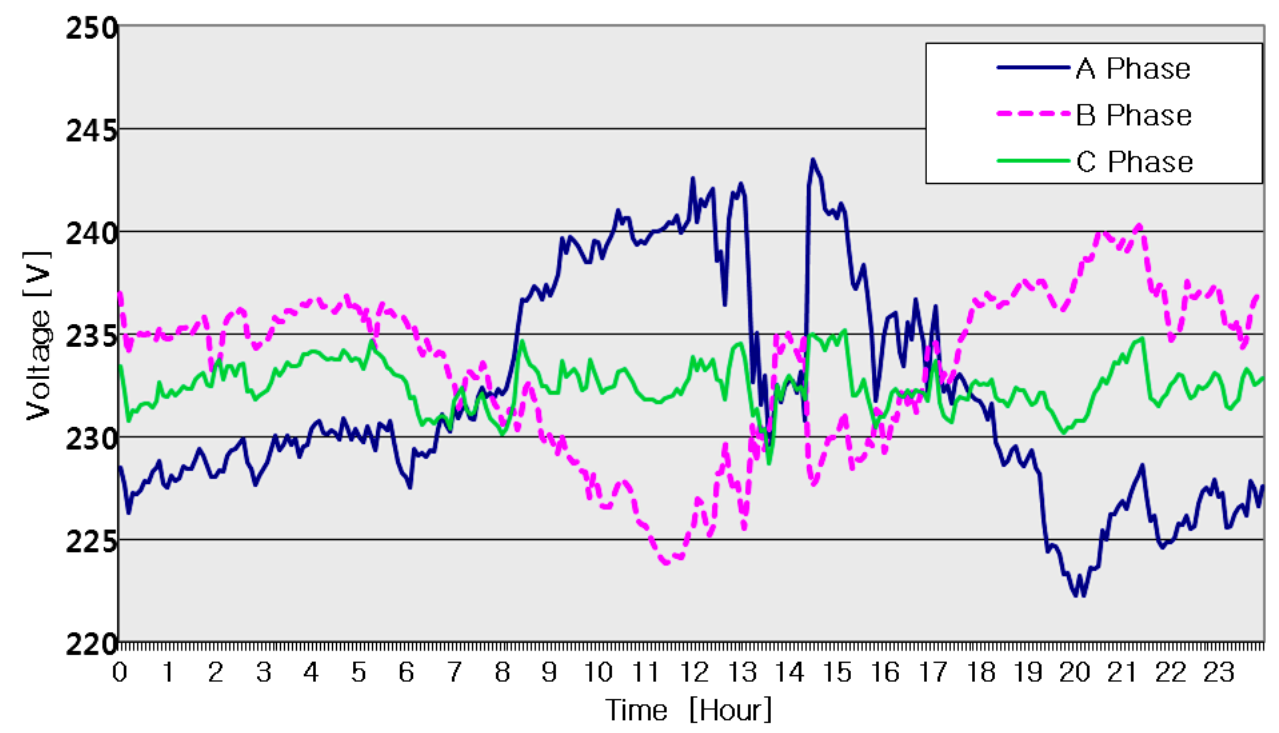

This paper presents a scheduling algorithm for an energy storage system (ESS) system in a direct current (DC) grid that is installed to regulate the distribution system voltage for optimal operation despite any fluctuations in the PV generation [2]. This algorithm is based on the power injection information obtained from smart metering devices. The smart metering devices measure the power injection at each point of common coupling (PCC) and transmit the information to a data concentrator. With the presented system, the optimal ESS charging schedule can be determined by satisfying the voltage regulation requirements. The main objective of this paper is to propose an ESS control algorithm by considering complementary operation among all the ESSs, and not only the individual ESS control. 


\section{Impact of ESS Scheduling on the Distribution System Voltage}

\subsection{Distribution System}

The distribution network at the Cheon-an site is a candidate for DC distribution implementation because of its high PV penetration. The DC system, which requires only voltage control, can benefit from system controllability because delivering power in the alternating current (AC) system requires control on the voltage, frequency and phase angle. Furthermore, the upper-side feeder-header AC/DC converter, which enables regulation of the distribution line voltage, has another benefit. In terms of efficiency, the DC distribution system is considered as a prospective system according to the increase in the DC-based loads. The DC distribution system has many advantages such as feasible connection of the distributed energy sources and reduction of the conversion losses for DC-based loads; therefore, it is very suitable for distribution systems, especially for the Cheon-an distribution system case. Therefore, this paper assumes that the distribution system is a DC distribution environment. As shown in Figure 2, the DC distribution system is composed of power electronic converters and a DC link. The ESS systems are applied at every PCC to compensate for the drawbacks of the DG systems, which affect the distribution system voltage.

Figure 2. Configuration of the DC distribution system.

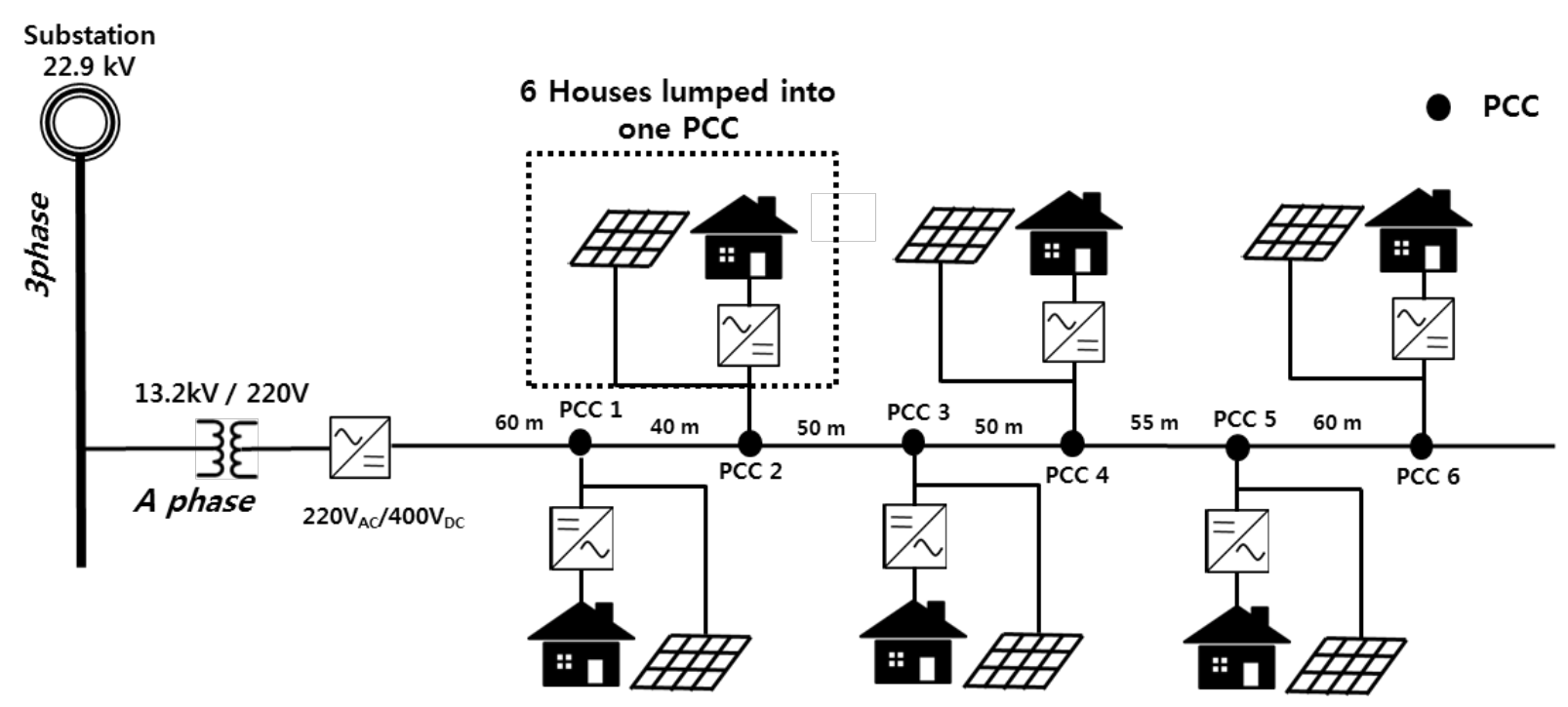

\subsubsection{Efficiency Analysis for the DC Distribution System}

In order to verify the efficiency of the DC distribution system, the efficiency comparison analysis between the $\mathrm{AC}$ and the DC distribution configuration, which is composed of residential loads, is performed. As summarized in Table 1, the composition of a residential load is assumed to be divided into three types: purely DC, DC conversion requiring AC, and purely AC loads. The composition ratio of each type of load is assumed to be $30 \%, 40 \%$ and $30 \%$, respectively. In addition, the conversion step of each type of load is different according to the distribution system configuration, whether it is AC or DC. With regard to the converter efficiency, two types of efficiency are considered. One is the efficiency regarding the type of converter. As shown in Figure 3, the higher the capacity of a 
converter, the higher the efficiency is, and the $\mathrm{AC} / \mathrm{DC}$ converter has the lower efficiency when compared with the DC/DC and DC/AC converters. The other efficiency is based on the loading conditions of a converter, as shown in Figure 4. By considering these factors to calculate the distribution system efficiency, it is verified that the DC distribution system can have benefits in terms of system efficiency.

Table 1. Power conversion efficiency for each type of distribution configuration.

\begin{tabular}{|c|c|c|c|c|c|}
\hline \multirow{2}{*}{ Load type } & \multirow{2}{*}{ Composition ratio } & \multicolumn{2}{|c|}{ Conversion step } & \multicolumn{2}{|c|}{ Efficiency } \\
\hline & & AC system & DC system & AC system & DC system \\
\hline $\mathrm{DC}$ & $30 \%$ & $\mathrm{AC} / \mathrm{DC}$ and $\mathrm{DC} / \mathrm{DC}$ & $\mathrm{DC} / \mathrm{DC}$ & $67.49 \%$ & $89.38 \%$ \\
\hline $\mathrm{DC}$ converted to $\mathrm{AC}$ & $40 \%$ & $\mathrm{AC} / \mathrm{DC}$ and $\mathrm{DC} / \mathrm{AC}$ & $\mathrm{DC} / \mathrm{AC}$ & $69.60 \%$ & $90.77 \%$ \\
\hline $\mathrm{AC}$ & $30 \%$ & - & $\mathrm{DC} / \mathrm{AC}$ & - & $90.54 \%$ \\
\hline \multicolumn{2}{|c|}{ PV } & $\mathrm{DC} / \mathrm{AC}$ & $\mathrm{DC} / \mathrm{DC}$ & $90.93 \%$ & $89.69 \%$ \\
\hline \multicolumn{2}{|c|}{$\mathrm{AC} / \mathrm{DC}$ feeder-header converter } & - & $\mathrm{AC} / \mathrm{DC}$ & - & $88.54 \%$ \\
\hline \multicolumn{4}{|c|}{ Total distribution system efficiency } & $81.51 \%$ & $83.63 \%$ \\
\hline
\end{tabular}

Figure 3. Converter efficiency for each converter type.

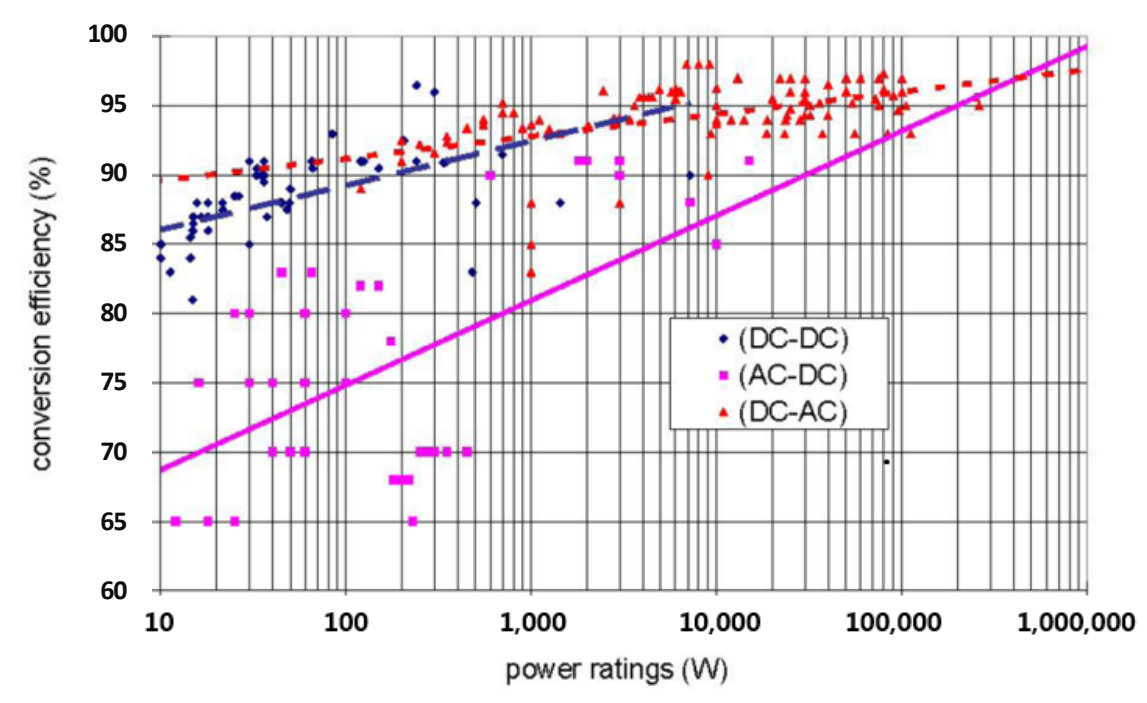

Figure 4. Converter efficiency according to the loading condition.

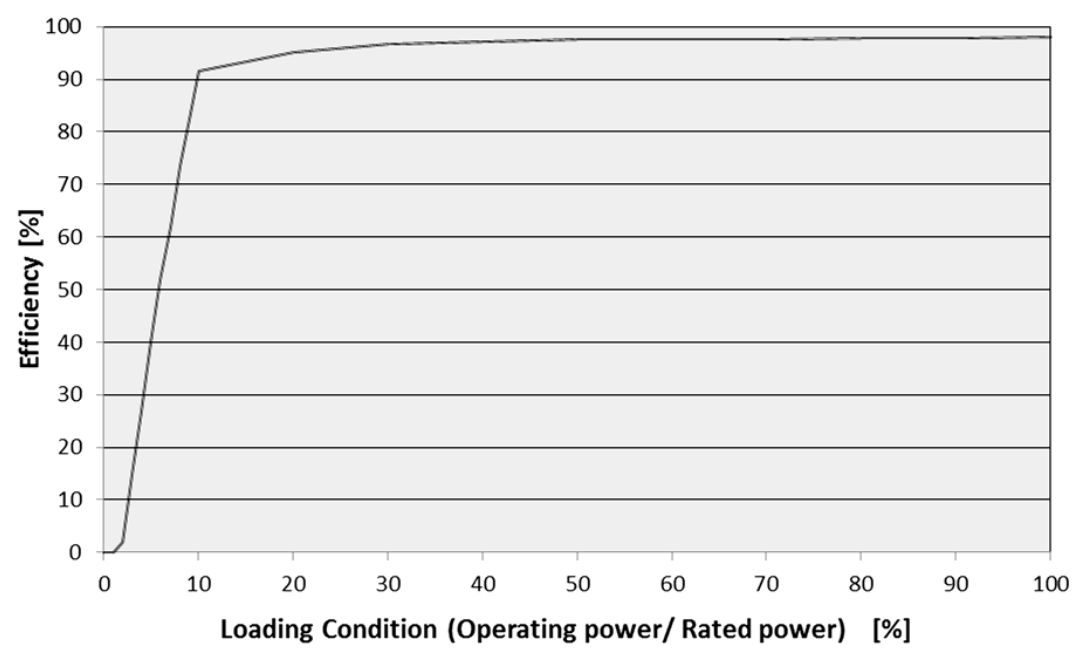




\subsection{Impact of Distributed Generation on the Distribution System Voltage}

The increasing diffusion of DGs such as PVs introduces voltage regulation problems in distribution systems. When the penetration of DGs is high in a distribution system, the system has the possibility of the distribution line voltage increasing and exceeding the allowable voltage limit because of the reverse power flow. DG based on renewable energy sources is susceptible to changes in the weather and environmental conditions, therefore, the amount of power generated depends strongly on those conditions. For this reason, the amount of voltage fluctuation is difficult to predict.

In the KEPCO system, the PV-concentrated areas in the low-voltage distribution systems, such as the Cheon-an distribution system, generally experience high-voltage phenomena. During periods of high insolation, excessive power from the PV sources flows along each branch; this reverse power flow causes a rise in voltage. The voltage at the A phase, which has many PVs in the distribution line, experiences a higher voltage when compared with the other phases during periods of high PV generation. As the KEPCO operating voltage range is restricted, the PV penetration is limited by the voltage regulation problems.

The extent of voltage fluctuation depends on the power system condition such as the distribution line parameters, distribution pattern of the DG, and output generation of the DG devices. Equation (1) shows the interrelation between the voltage fluctuation and the power inflow in a radial distribution power system. On the basis of Equation (1), when the power injection is concentrated on the lower side of distribution line, the extent of voltage fluctuation is more severe [3]:

$$
\begin{gathered}
\Delta V_{n}=i_{1} Z_{1}+i_{2} \sum_{k=1}^{2} Z_{k}+\cdots+i_{n} \sum_{k=1}^{n} Z_{n} \\
=Z_{1} \sum_{k=1}^{n} \frac{P_{k}}{V}+Z_{2} \sum_{k=2}^{n} \frac{P_{k}}{V}+\cdots+Z_{n} \frac{P_{n}}{V} \\
=\frac{P_{1}}{V} Z_{1}+\frac{P_{2}}{V} \sum_{k=1}^{2} Z_{k}+\cdots+\frac{P_{n}}{V} \sum_{k=1}^{n} Z_{n}
\end{gathered}
$$

\subsection{Effect of the Energy Storage System on Voltage Regulation}

High generation within DGs and low load conditions lead to inversion of the power flow, which results in voltage rises. In order to solve this issue, this paper suggests the use of an ESS system for voltage regulation. The simulated system data are based on the Cheon-an distribution system, which frequently experiences voltage rise problems. The ESS can be used to store part of the energy produced during peak-generation periods by the PV and re-dispatch it during the evening or overnight.

This paper presents an algorithm for the ESS scheduling of power required for voltage support. This scheduling algorithm is based on the power injection data measured at the PCCs. These data are measured by a smart metering system and transmitted to a data concentrator, which estimates the optimal ESS scheduling condition while performing distribution line voltage regulation. By using the accurate system data from a smart meter, the current condition of the distribution system can be more precisely estimated. The main objective of the presented ESS scheduling algorithm is to control all the 
ESSs complementally, and not individually. Therefore, the optimized capacity of each ESS for voltage regulation can be derived $[4,5]$.

\section{Optimized ESS Scheduling to Compensate the Fluctuation in the Distribution System Voltage}

\subsection{Power Flow Calculation for the DC Distribution System}

As the DGs are more commonly connected to low-voltage distribution systems, voltage stability has become a critical issue for power system operation. Voltage regulation can be disrupted by the fluctuations in the power inflow from the DGs. The assessment of voltage supported by ESS to ensure adequate distribution system voltage profile must be conducted with a power system analysis. Most power system analyses are based on power flow calculations. Therefore, to estimate a complementary charging schedule for the ESSs required for voltage regulation, system analysis based on the voltage and power loading conditions is required in advance. This section presents a methodology for the DC distribution system power flow estimation in order to acquire accurate information on the distribution system condition. The DC power flow analysis is a method to determine the optimal ESS operation schedule for all the ESSs in the distribution system to operate complementally for voltage regulation $[6,7]$.

As shown in Figure 5, the power flow calculation is based on Kirchhoff's circuit law in electric power networks and comprises a set of nonlinear algebraic equations representing real, reactive power injection flow at each node. The nonlinear equations can be solved with an iterative algorithm such as the Newton-Raphson method. Equation (2) represents the AC power flow calculation, which is formulated with four variables at each bus: voltage magnitude, angle, and real and reactive power injection. The power flow calculation equation is a complex equation; therefore, it is necessary to separate the real and imaginary parts in order to apply the Newton-Raphson method:

$$
\begin{aligned}
& P_{k}=V_{k} \sum_{i=1}^{N} V_{i}\left[G_{k i} \cos \left(\theta_{k}-\theta_{i}\right)+B_{k i} \sin \left(\theta_{k}-\theta_{i}\right)\right] \\
& Q_{k}=V_{k} \sum_{i=1}^{N} V_{i}\left[G_{k i} \sin \left(\theta_{k}-\theta_{i}\right)-B_{k i} \cos \left(\theta_{k}-\theta_{i}\right)\right]
\end{aligned}
$$

Figure 5. Power flow in a multi-bus system (based on Kirchhoff's law).

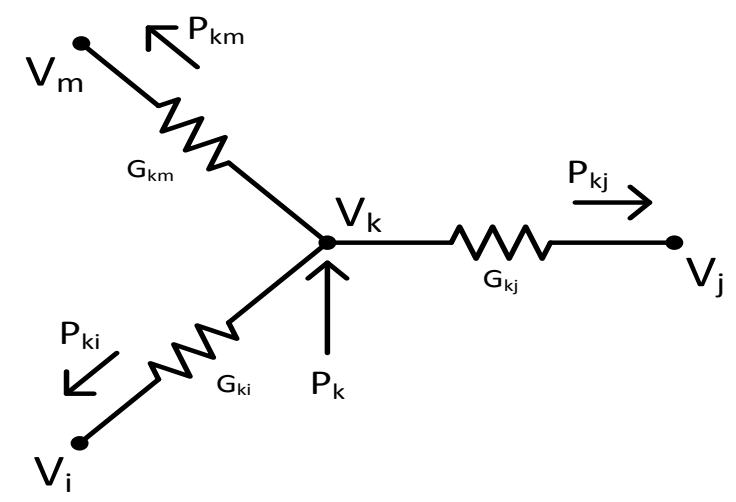


Like the AC power flow calculation, the power flow in DC system can be expressed as Equation (3). Only two variables, voltage and real power injection data, are required to calculate the DC power flow because the DC system has no components related to reactive power and inductance. Therefore, the reactive power term $\left(Q_{k}\right)$ and inductance term $\left(B_{k i}\right)$ are excluded from Equation (2). The voltage angle difference $\left(\theta_{k}-\theta_{i}\right)$ is zero:

$$
\begin{gathered}
P_{k}=V_{k} \sum_{i=1}^{N} V_{i}\left[G_{k i}\right] \\
{\left[\begin{array}{c}
I_{1} \\
I_{2} \\
I_{3} \\
\vdots
\end{array}\right]=\left[\begin{array}{cccc}
G_{11} & G_{12} & G_{13} & \ldots \\
G_{21} & G_{22} & G_{23} & \ldots \\
G_{31} & G_{32} & G_{33} & \ldots \\
\vdots & \vdots & \vdots & \ddots
\end{array}\right]\left[\begin{array}{c}
V_{1} \\
V_{2} \\
V_{3} \\
\vdots
\end{array}\right]}
\end{gathered}
$$

The Newton- Raphson method is implemented using Equation (4) to solve the DC power flow equation. The DC power flow Jacobian matrix is only composed of conductance components, and the Newton- Raphson iteration for DC power flow is performed as a function of the correlation between the voltage and the real power injection.

The objective of this paper is to estimate the optimal ESS charging schedule in order to maintain the voltage stability within the regulation range. Therefore, it is necessary to induce the formulation regarding the correlation between the voltage and the power injection at each PCC. From the DC power flow Equations (3) and (4), the voltage and power injection correlation equation are derived in a matrix form as in Equations (5)-(7). This correlation matrix represents control of the power injection to adjust the distribution line voltages:

$$
\begin{gathered}
\Delta P_{i}=\sum_{k=1}^{N} \frac{\partial P_{i}}{\partial V_{k}} \Delta V_{k} \\
{\left[\begin{array}{c}
\Delta P_{1} \\
\Delta P_{2} \\
\Delta P_{3} \\
\vdots
\end{array}\right]=\left[\begin{array}{cccc}
\frac{\partial P_{1}}{\left(\frac{\partial V_{1}}{V_{1}}\right)} & \frac{\partial P_{1}}{\left(\frac{\partial V_{2}}{V_{2}}\right)} & \frac{\partial P_{1}}{\left(\frac{\partial V_{3}}{V_{3}}\right)} & \ldots \\
\frac{\partial P_{2}}{\left(\frac{\partial V_{1}}{V_{1}}\right)} & \frac{\partial P_{2}}{\left(\frac{\partial V_{2}}{V_{2}}\right)} & \frac{\partial P_{2}}{\left(\frac{\partial V_{3}}{V_{3}}\right)} & \ldots \\
\frac{\partial P_{3}}{\left(\frac{\partial V_{1}}{V_{1}}\right)} & \frac{\partial P_{3}}{\left(\frac{\partial V_{2}}{V_{2}}\right)} & \frac{\partial P_{3}}{\left(\frac{\partial V_{3}}{V_{3}}\right)} & \ldots \\
\vdots & \vdots & \ddots
\end{array}\right]\left[\begin{array}{c}
\frac{\Delta V_{1}}{V_{1}} \\
\frac{\Delta V_{2}}{V_{2}} \\
\frac{\Delta V_{3}}{V_{3}} \\
\vdots
\end{array}\right]} \\
\frac{\partial P_{i}}{\left(\frac{\partial V_{k}}{V_{k}}\right)}=V_{i} V_{k} G_{i k}
\end{gathered}
$$

\subsection{Complementary Optimal ESS Scheduling for Voltage Regulation}

3.2.1. Representation of the Complementary ESS Scheduling on the Basis of the Smart Metering Data

This paper presents an algorithm for the optimal operation of the ESS to regulate the distribution line voltage. The main contribution of this algorithm is the complementary operation between the 
ESSs. In order to complementally schedule all the ESSs in a distribution system, the power injection data at each PCC are required, and these data can be obtained by a smart metering system. The measured power injection data obtained by the smart meters at each PCC are transferred to a concentrator, which collects the entire distribution system information and estimates the current condition of the distribution system. From the power injection data, the distribution voltage can be derived as explained in the DC power flow calculation method. Therefore, the concentrator estimates the distribution voltage condition and provides an instruction on the control of the ESSs for the complementary operation between the ESSs [8]. Figure 6 represents the configuration of this distribution system, which is equipped with a smart meter system at each bus and a data concentrator.

Figure 6. Configuration of the distribution system equipped with a smart metering system.

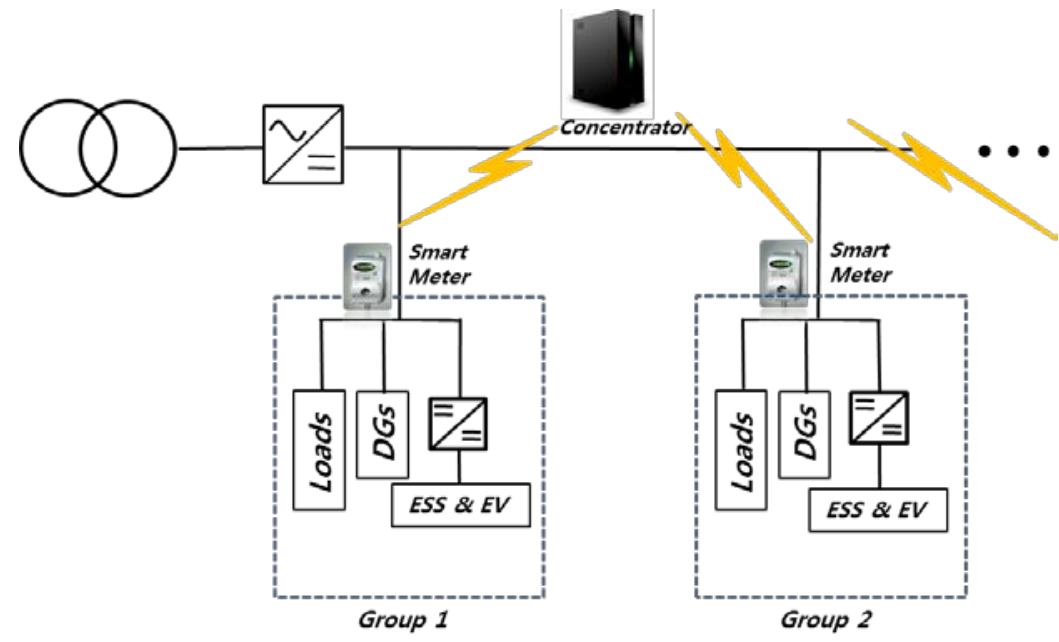

Case studies have been conducted with the real KEPCO distribution system data to demonstrate the ESS control algorithm. The Cheon-an distribution network in the KEPCO system comprises a roof-top PV generation at each house. In addition, six houses are lumped into one connection point, which is defined as the point of common coupling (PCC). This paper applies the OW-60 $\mathrm{mm}^{2}$ single-phase pi $(\pi)$ line parameter, which has a resistance, an inductance and a capacitance per unit length of $0.313(\Omega / \mathrm{km})$, $0.266(\mathrm{mH} / \mathrm{km})$, and $0.0013(\mu \mathrm{F} / \mathrm{km})$, respectively.

Each smart meter measures the loading condition at each PCC, and the voltage condition of the whole distribution system is estimated. By calculating the DC power flow on the basis of the measured information from the smart meter system, the distribution line voltage condition can be determined, whether the current voltage condition deviates from the normal range or not. When the estimated voltage condition is out of range, ESS charging is performed as instructed by the concentrator. The capacity of charging for each ESS is calculated by considering the mutual influence between the PCCs [9].

\subsubsection{Complementally Optimized Scheduling for ESSs in a Distribution System}

The distribution line voltage can be calculated by using the DC power flow calculation as explained in Section 3.1. In the case that the distribution system is radial, the power flow at bus $i$ can be simplified as shown in Equation (8). The distribution line voltage is closely related to the power injection, and the individual power injection at each PCC affects not only the voltage of the connected 
PCC, but also the entire distribution line voltage. In this paper, in order to estimate the optimal ESS capacity for voltage regulation, the optimization function based on the genetic algorithm (GA) is used through MATLAB simulation [10,11]. In addition, the result of the algorithm is demonstrated through PSCAD/EMTDC simulation:

$$
P_{i}=V_{i}\left(V_{i-1} G_{(i-1) i}+V_{i} G_{i i}+V_{i+1} G_{i(i+1)}\right)
$$

During the periods of high DG generation, the voltage at a given PCC fluctuates above the permitted voltage regulation range. The amount of overvoltage can be calculated by performing the DC power flow calculation with the power injection data from obtained the smart meters, and the ESS can absorb an adequate power in order to maintain the voltage within the limits. As expressed in Equation (8), the voltage at a given PCC depends not only on the power usage at the connected PCC, but also on the condition of the adjacent bus with mutual influence. Therefore, when the ESS operation scheduling is estimated, the mutual influence between the PCCs must be considered.

By using the data from the smart metering system, this paper introduces a complementally optimized ESS scheduling algorithm for voltage regulation for all the ESSs, and not only for the individual ESS control independently. The required power, which can be generated or absorbed by the ESSs, is calculated for the voltage regulation $\left(388 \mathrm{~V}<V_{d c}<412 \mathrm{~V}\right)$.

The presented ESS scheduling algorithm considers all the available ESSs in the distribution system to regulate the distribution line voltage; therefore, the objective function of optimization is to minimize the capacity of all the ESSs with satisfaction under the normal voltage operating condition as expressed in Equations (9)-(11):

$$
\begin{gathered}
\text { basic function: } P^{P C C}=\left(P_{D G}-P_{L}\right)^{\text {scheduled }}+P_{E S S} \\
\text { objective function: } \sum_{k=2}^{N}\left(P_{k}\left(V_{k-1}, V_{k}, V_{k+1}\right)-P_{k}^{\text {scheduled }}\right)^{2}
\end{gathered}
$$

with voltage regulation constraints:

$$
388 \mathrm{~V}<V_{k}<412 \mathrm{~V}(k=1 \sim N)
$$

By performing an iterative GA process, the best result is stochastically selected. The optimized $P$ for each ESS is calculated while monitoring whether the distribution line voltages at every PCC satisfy the voltage regulation requirements. Through this process, the $P^{\text {new }}$ value required for voltage regulation is updated as expressed in Equation (12). In addition, from this result, the capacity of each ESS is determined. Figure 7 shows the flow chart of this entire process:

$$
P_{i}^{\text {new }}=P_{i}^{\text {old }}\left(1+\frac{\Delta P_{i}^{\text {old }}}{P_{i}^{\text {old }}}\right)
$$

The algorithm is divided into three sections. The first section is the part where the system configuration is entered, and the power injection data of each PCC are collected from the smart metering system. In the second section the DC power flow calculation is performed on the basis of the collected power injection data. Through the DC power flow calculation, it can be estimated whether the distribution line voltage at each PCC is within the normal operation range or not. The third section 
involves the ESS scheduling process. In this part, the optimization using the GA is performed to determine the optimal operation condition for each ESS.

Figure 7. ESS charge scheduling algorithm for voltage regulation.

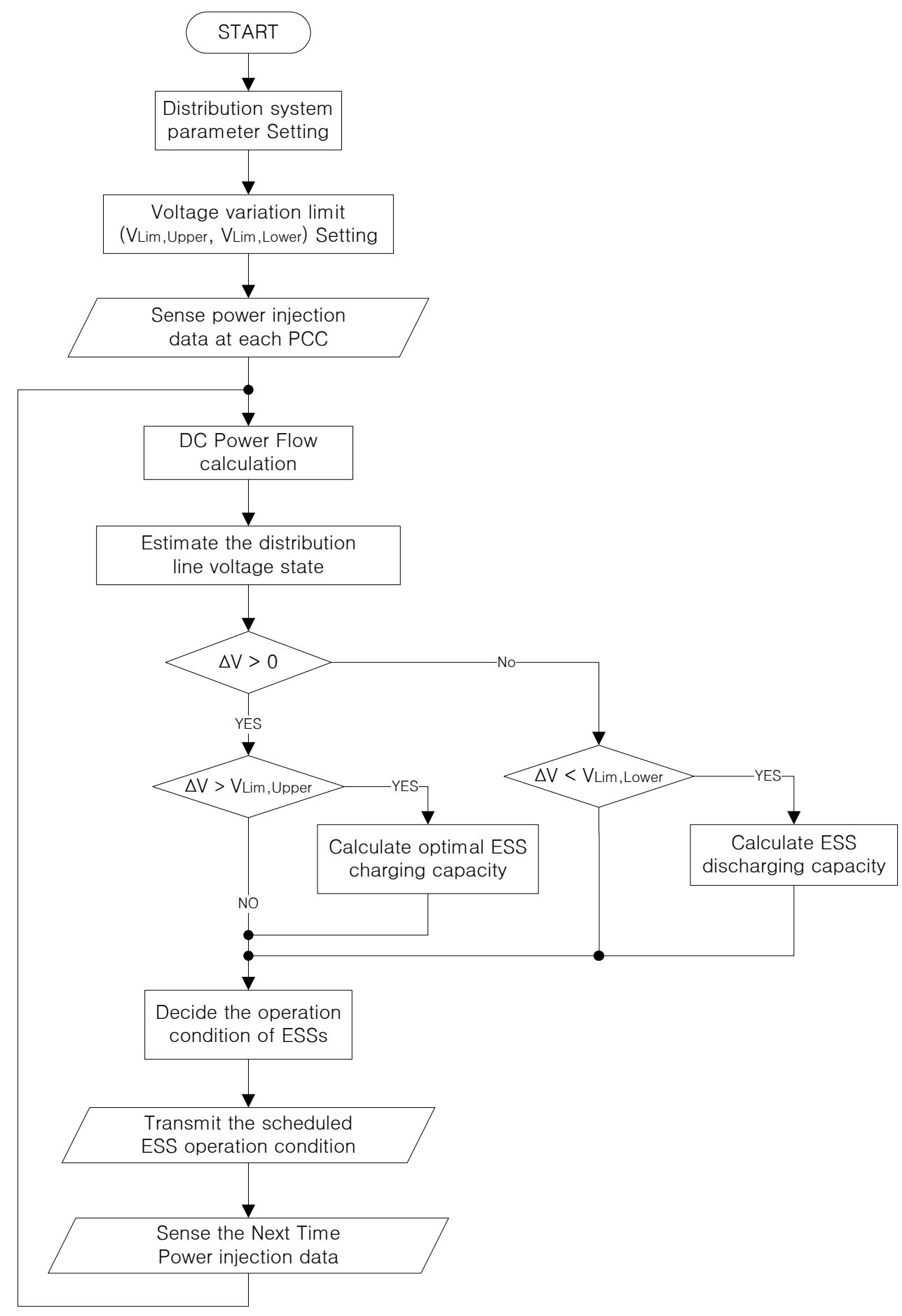

3.2.3. Methodologies for the Discharging Schedule of ESSs in a Distribution System

In order to regulate the voltage during the periods of high PV generation by using the ESSs, the state of charging (SOC) of the ESSs should be considered to ensure an adequate capacity of the ESSs. In order to ensure the capacity of an ESS for voltage regulation, the SOC of the ESSs must be lowered 
by adequately discharging the power during the relatively low DG generation and high load periods. The discharge power from the ESSs can cause the distribution line voltage fluctuation. This paper suggests two different methods in order to adequately discharge the ESS power. The main objective of this discharging algorithm is to enable the distribution line voltage operate closer to the normal voltage.

The first method is based on the historical power flow tendency. In this case, the charged power during the periods of high PV generation is discharged during historically low DG generation and high load periods. In this paper, it is assumed that the discharging periods are between 7 and $11 \mathrm{pm}$, and the charged energy is equally discharged during those periods. When the ESS SOC reaches the lowest level, the discharge operation is stopped.

The second method optimally discharges the available ESS power to increase the distribution line voltage for it to be closer to the normal voltage. This is performed through simulation by increasing the lower voltage limit during the optimization process. In this simulation, the lower voltage limit for the optimization is set as $393 \mathrm{~V}$. Therefore, when the distribution line voltage reaches below $393 \mathrm{~V}$, ESS discharging is complementally performed to compensate the voltage with optimal use of the ESS power.

\section{Simulation Results}

In order to estimate the optimal ESS capacity at each PCC for voltage regulation, MATLAB simulation is performed with the real KEPCO distribution data. The MATLAB simulation result is implemented through a PSCAD/EMTDC simulation for demonstration. In this paper, it is assumed that the PV penetration can be increased from the current $2.5-\mathrm{kW}$ capacity in order to verify the ESS effect under the overvoltage condition. Furthermore, in order to verify the influence of the PV distribution state in a distribution system, four case studies are conducted: equal distribution and clumped distribution on the upper side, middle side, and lower side of the distribution line. Figure 8 shows the profile of the input data for the load demands at six PCCs, and Figure 9 represents the PV output generation for one day.

Figure 8. Load profiles for one day at six PCCs (each PCC consists of six houses).

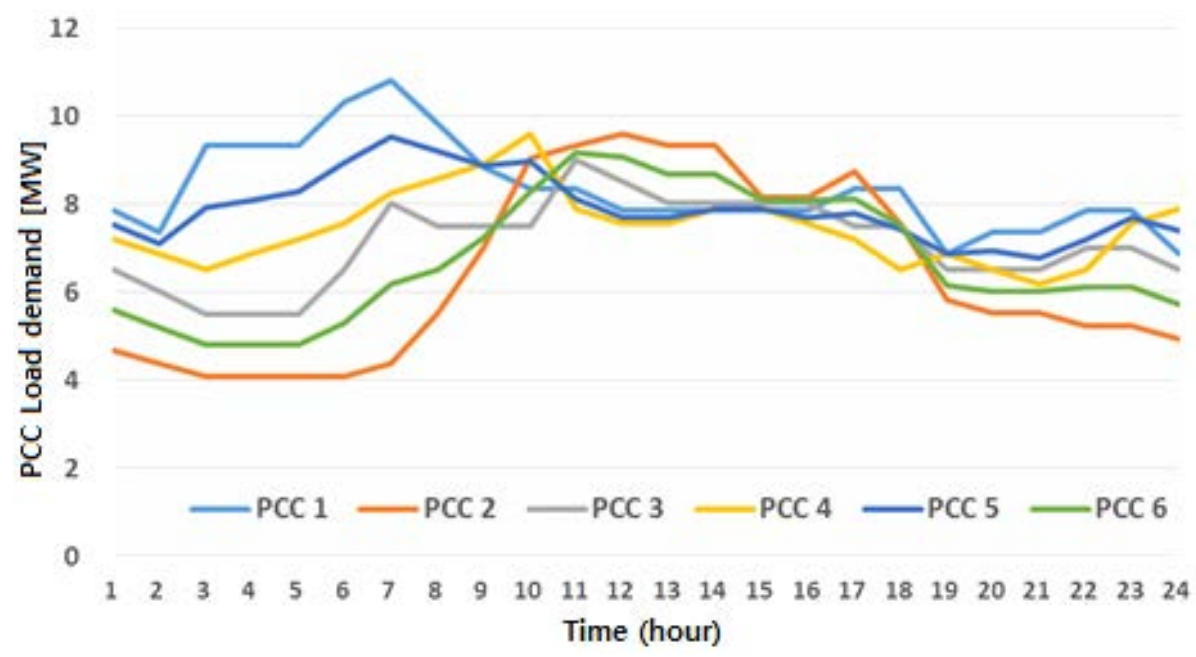


Figure 9. Output generation of a PV on a house (2.5-kW PV).

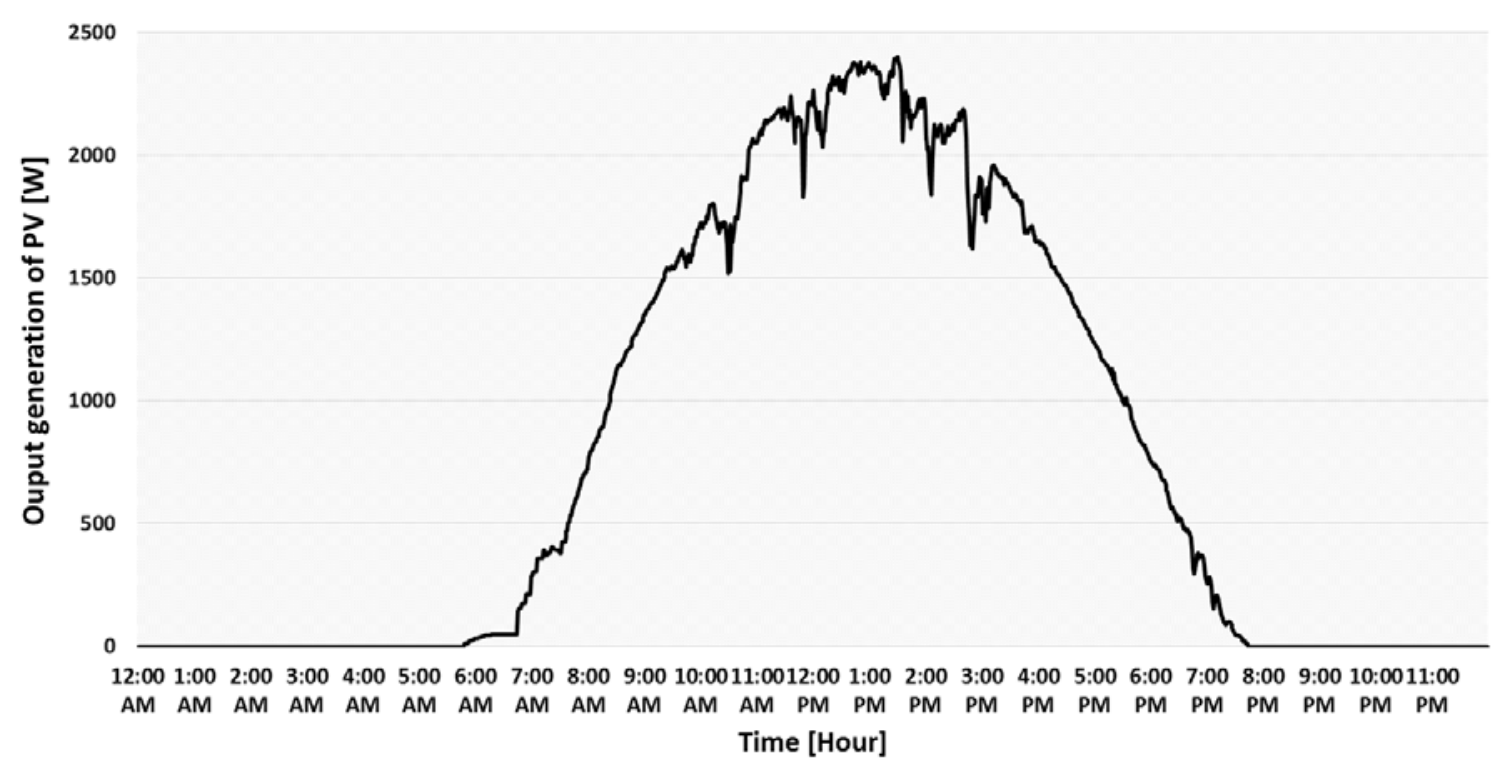

\subsection{Complementally Optimized ESS Operation Scheduling for Voltage Regulation}

As shown in Figure 10, when the PV generation is greater than $4.0 \mathrm{~kW}$, some of the PCCs on the distribution line experience overvoltage problems. In order to verify the performance of the ESS scheduling algorithm for voltage regulation, this algorithm is applied to the Cheon-an distribution system that is composed of 36 houses, each having an increased PV capacity $4.0-\mathrm{kW}$ peak. The DC power flow calculation is performed to estimate the ESS capacity for voltage regulation, and the calculation result is summarized in Table 2.

Figure 10. Voltage profile for one day $(\mathrm{PV}=4 \mathrm{~kW})$.

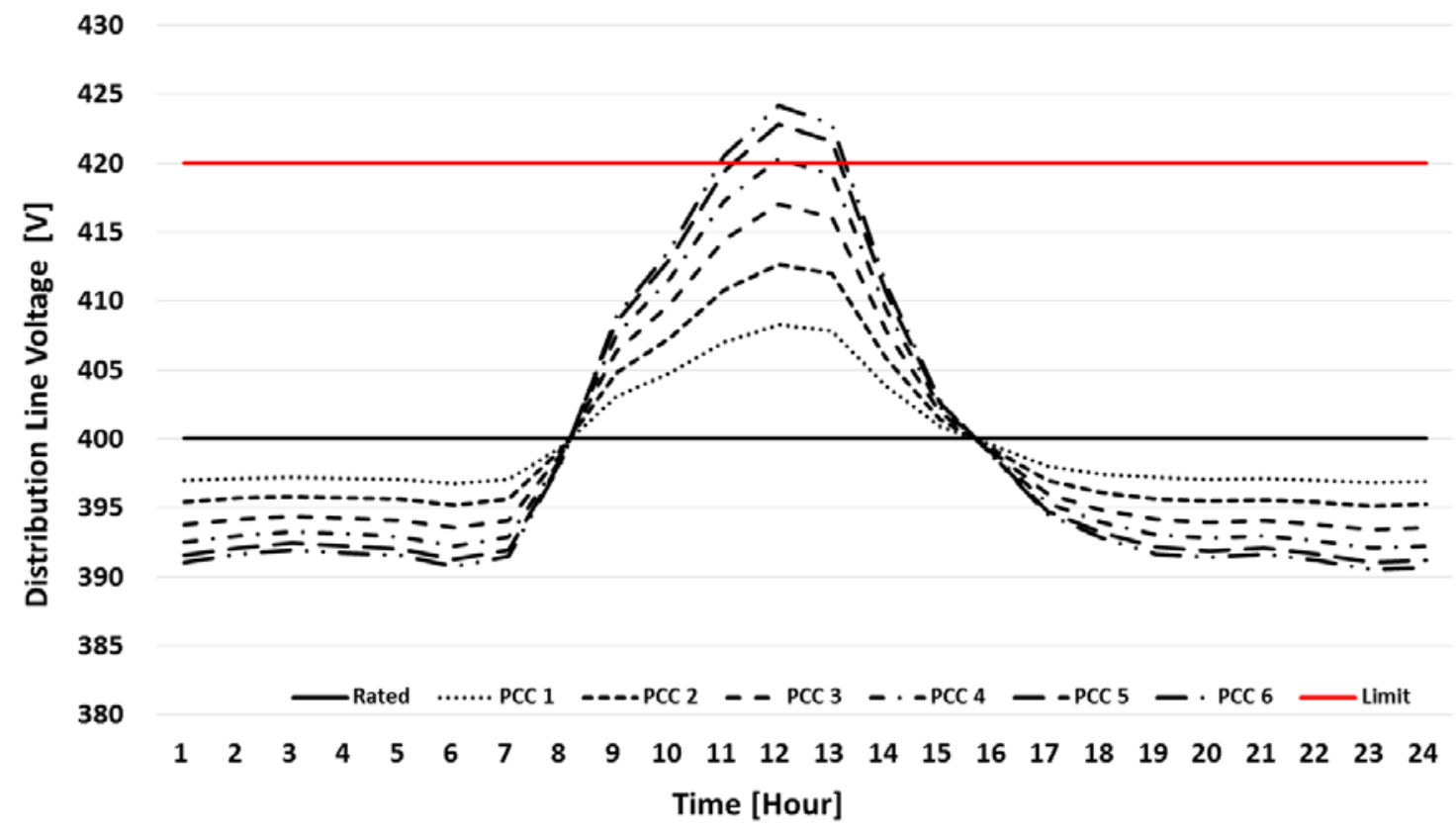


Table 2. ESS charging schedule and capacity for voltage regulation $(4.0-\mathrm{kW} P V$ is equally distributed).

\begin{tabular}{cccccccc}
\hline Time & PCC 1 & PCC 2 & PCC 3 & PCC 4 & PCC 5 & PCC 6 & Total \\
\hline 11:00-12:00 & $124 \mathrm{~W}$ & $202 \mathrm{~W}$ & $296 \mathrm{~W}$ & $390 \mathrm{~W}$ & $501 \mathrm{~W}$ & $614 \mathrm{~W}$ & \\
12:00-13:00 & $987 \mathrm{~W}$ & $1609 \mathrm{~W}$ & $2362 \mathrm{~W}$ & $3115 \mathrm{~W}$ & $4011 \mathrm{~W}$ & $4920 \mathrm{~W}$ & $31 \mathrm{~kW} \cdot \mathrm{h}$ \\
13:00-14:00 & $666 \mathrm{~W}$ & $1086 \mathrm{~W}$ & $1594 \mathrm{~W}$ & $2102 \mathrm{~W}$ & $2706 \mathrm{~W}$ & $3318 \mathrm{~W}$ & \\
Capacity & $1777 \mathrm{~W} \cdot \mathrm{h}$ & $2897 \mathrm{~W} \cdot \mathrm{h}$ & $4254 \mathrm{~W} \cdot \mathrm{h}$ & $5608 \mathrm{~W} \cdot \mathrm{h}$ & $7219 \mathrm{~W} \cdot \mathrm{h}$ & $8853 \mathrm{~W} \cdot \mathrm{h}$ & \\
\hline
\end{tabular}

As shown in Figure 11, by using this ESS control algorithm, the distribution line voltage can satisfy the voltage regulation requirement. The main objective of this paper is to propose an ESS control algorithm by considering the complementary operation among all the ESSs, and not the individual ESS control. With the presented algorithm, the optimal ESS charging schedule which satisfies the voltage regulation requirement is determined. As depicted in Figure 12, the ESSs at PCCs 1-3, which do not experience overvoltage problems, are also charged to regulate the voltage of the other PCCs. With the presented algorithm, it is verified that the ESSs are charged to operate complementarily even when the adjacent PCC does not experience the voltage problem.

Figure 11. Voltage profile compensated by the ESSs.

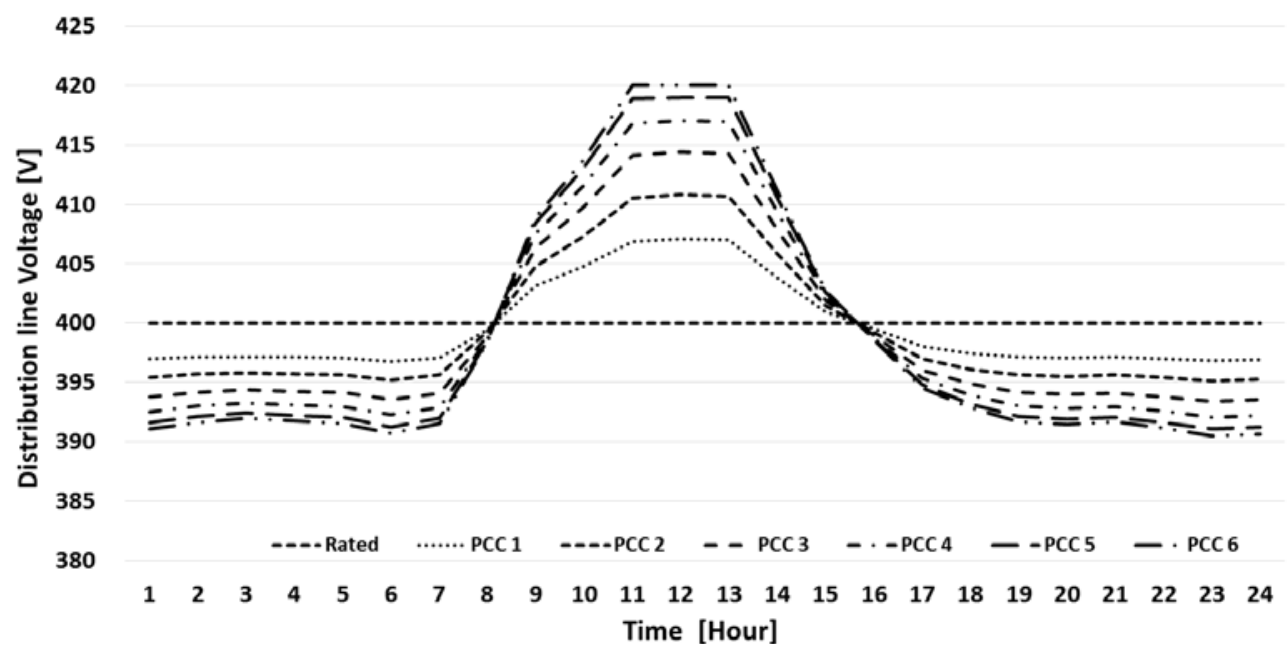

Figure 12. Complementary ESS operation for voltage regulation.

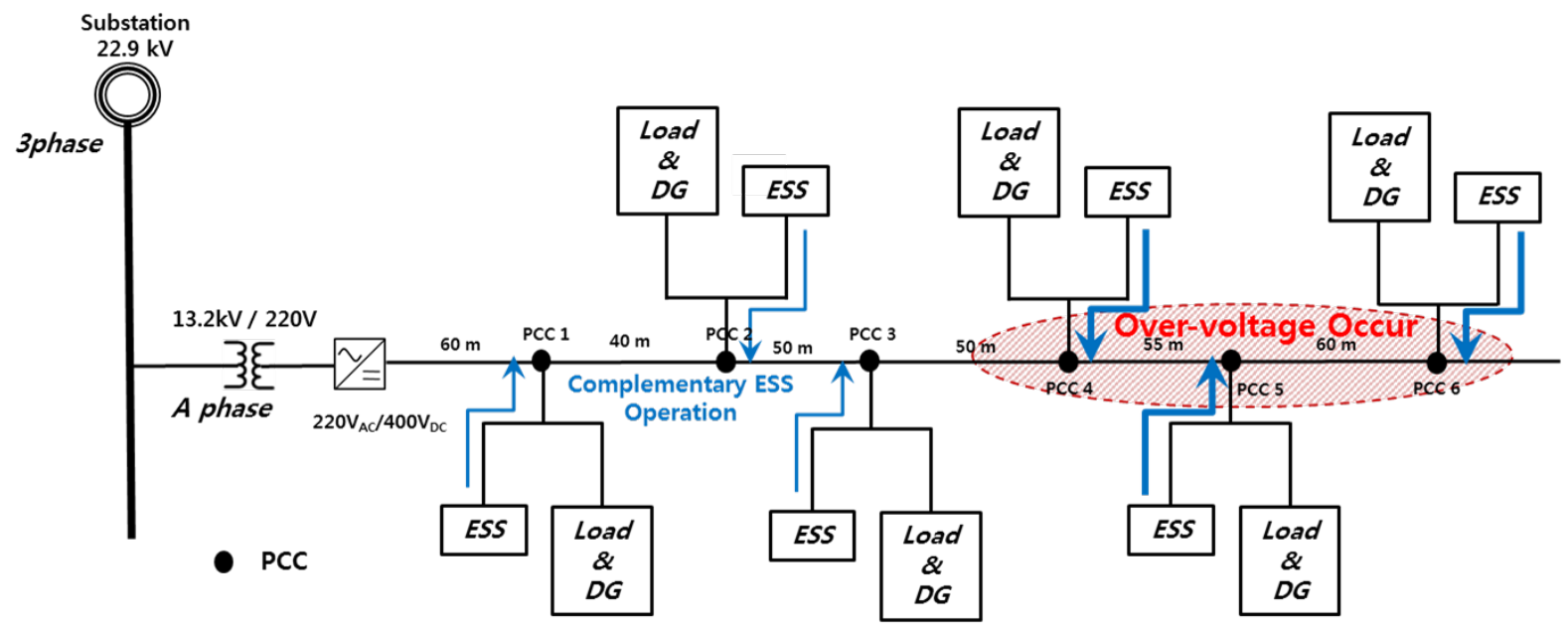




\subsection{Comparison of the ESS Scheduling with Different PV Distributions in the Distribution Line}

For the analysis of the influence of the PV distribution state on the ESS capacity, three case studies are conducted in different PV distribution states. Table 3 summarizes the charging schedule for the case that most of the PVs are connected on the upper side of the distribution line, PCCs 1-3. Table 4 summarizes the case that most of the PVs are connected on the lower side of the distribution line, PCCs 4-6, and Table 5 summarizes the case that most of the PVs are connected on the middle side. The total sum of the PV capacities is the same for all the cases.

From this result, it is verified that all the ESSs in the distribution line operate complementally to minimize the total ESS capacity. As can be observed from the simulation result, a high ESS capacity is required on the lower side of the distribution line. Furthermore, a high-capacity PV connected on the lower side of the distribution line requires a high ESS capacity. Therefore, when the ESS installation is considered in a distribution line, it is necessary to consider efficient distribution of the ESSs in advance.

Table 3. ESSs charging schedule and capacity (case 2: most of the PVs are distributed on the upper side).

\begin{tabular}{cccccccc}
\hline Time & PCC 1 & PCC 2 & PCC 3 & PCC 4 & PCC 5 & PCC 6 & Total \\
\hline 11:00-12:00 & $637 \mathrm{~W}$ & $1,038 \mathrm{~W}$ & $1,525 \mathrm{~W}$ & $2,013 \mathrm{~W}$ & $2,594 \mathrm{~W}$ & $3,182 \mathrm{~W}$ & \\
$12: 00-13: 00$ & $1,550 \mathrm{~W}$ & $2,528 \mathrm{~W}$ & $3,716 \mathrm{~W}$ & $4,909 \mathrm{~W}$ & $6,330 \mathrm{~W}$ & $7,768 \mathrm{~W}$ & $59 \mathrm{~kW} \cdot \mathrm{h}$ \\
$13: 00-14: 00$ & $1,204 \mathrm{~W}$ & $1,962 \mathrm{~W}$ & $2,884 \mathrm{~W}$ & $3,810 \mathrm{~W}$ & $4,912 \mathrm{~W}$ & $6,027 \mathrm{~W}$ & \\
Capacity & $3,392 \mathrm{~W} \cdot \mathrm{h}$ & $5,529 \mathrm{~W} \cdot \mathrm{h}$ & $8,126 \mathrm{~W} \cdot \mathrm{h}$ & $10,734 \mathrm{~W} \cdot \mathrm{h}$ & $13,837 \mathrm{~W} \cdot \mathrm{h}$ & $16,978 \mathrm{~W} \cdot \mathrm{h}$ & \\
\hline
\end{tabular}

Table 4. ESSs charging schedule and capacity (case 3: most of the PVs are distributed on the lower side).

\begin{tabular}{cccccccc}
\hline Time & PCC 1 & PCC 2 & PCC 3 & PCC 4 & PCC 5 & PCC 6 & Total \\
\hline 11:00-12:00 & $1,377 \mathrm{~W}$ & $2,245 \mathrm{~W}$ & $3,295 \mathrm{~W}$ & $4,340 \mathrm{~W}$ & $5,586 \mathrm{~W}$ & $6852 \mathrm{~W}$ & \\
12:00-13:00 & $2,375 \mathrm{~W}$ & $3,873 \mathrm{~W}$ & $5,686 \mathrm{~W}$ & $7,491 \mathrm{~W}$ & $9,646 \mathrm{~W}$ & $11,834 \mathrm{~W}$ & \\
13:00-14:00 & $1,987 \mathrm{~W}$ & $3,240 \mathrm{~W}$ & $4,756 \mathrm{~W}$ & $6,265 \mathrm{~W}$ & $8,066 \mathrm{~W}$ & $9,895 \mathrm{~W}$ & \\
Capacity & $5,740 \mathrm{~W} \cdot \mathrm{h}$ & $9,358 \mathrm{~W} \cdot \mathrm{h}$ & $13,738 \mathrm{~W} \cdot \mathrm{h}$ & $18,098 \mathrm{~W} \cdot \mathrm{h}$ & $23,299 \mathrm{~W} \cdot \mathrm{h}$ & $28,581 \mathrm{~W} \cdot \mathrm{h}$ & \\
\hline
\end{tabular}

Table 5. ESSs charging schedule and capacity (case 4: most of the PVs are distributed on the middle side).

\begin{tabular}{cccccccr}
\hline Time & PCC 1 & PCC 2 & PCC 3 & PCC 4 & PCC 5 & PCC 6 & Total \\
\hline 11:00-12:00 & $976 \mathrm{~W}$ & $1,590 \mathrm{~W}$ & $2,332 \mathrm{~W}$ & $3,076 \mathrm{~W}$ & $3,969 \mathrm{~W}$ & $4,872 \mathrm{~W}$ & \\
12:00-13:00 & $1,928 \mathrm{~W}$ & $3,140 \mathrm{~W}$ & $4,607 \mathrm{~W}$ & $6,081 \mathrm{~W}$ & $7,853 \mathrm{~W}$ & $9,645 \mathrm{~W}$ & \\
13:00-14:00 & $1,562 \mathrm{~W}$ & $2,544 \mathrm{~W}$ & $3,733 \mathrm{~W}$ & $4,927 \mathrm{~W}$ & $6,361 \mathrm{~W}$ & $7,812 \mathrm{~W}$ & $77 \mathrm{~W} \cdot \mathrm{h}$ \\
Capacity & $4,466 \mathrm{~W} \cdot \mathrm{h}$ & $7,275 \mathrm{~W} \cdot \mathrm{h}$ & $10,673 \mathrm{~W} \cdot \mathrm{h}$ & $14,085 \mathrm{~W} \cdot \mathrm{h}$ & $18,185 \mathrm{~W} \cdot \mathrm{h}$ & $22,330 \mathrm{~W} \cdot \mathrm{h}$ & \\
\hline
\end{tabular}

\subsection{ESS Discharging Schedule Simulation}

As shown in Figure 13, discharging the ESS power can change the voltage profile. By discharging the power at an appropriate time when the load is high and DG generation is low, the voltage can be compensated to be closer to the normal voltage. In this paper, two different algorithms are proposed to appropriately discharge the ESS power. The proposed discharging algorithms enable the distribution 
line voltage operate closer to the normal voltage. The simulated case is based on the system data which is defined as equally distributed case in Section 4.1.

Figure 13. Voltage compensation by using the ESSs.

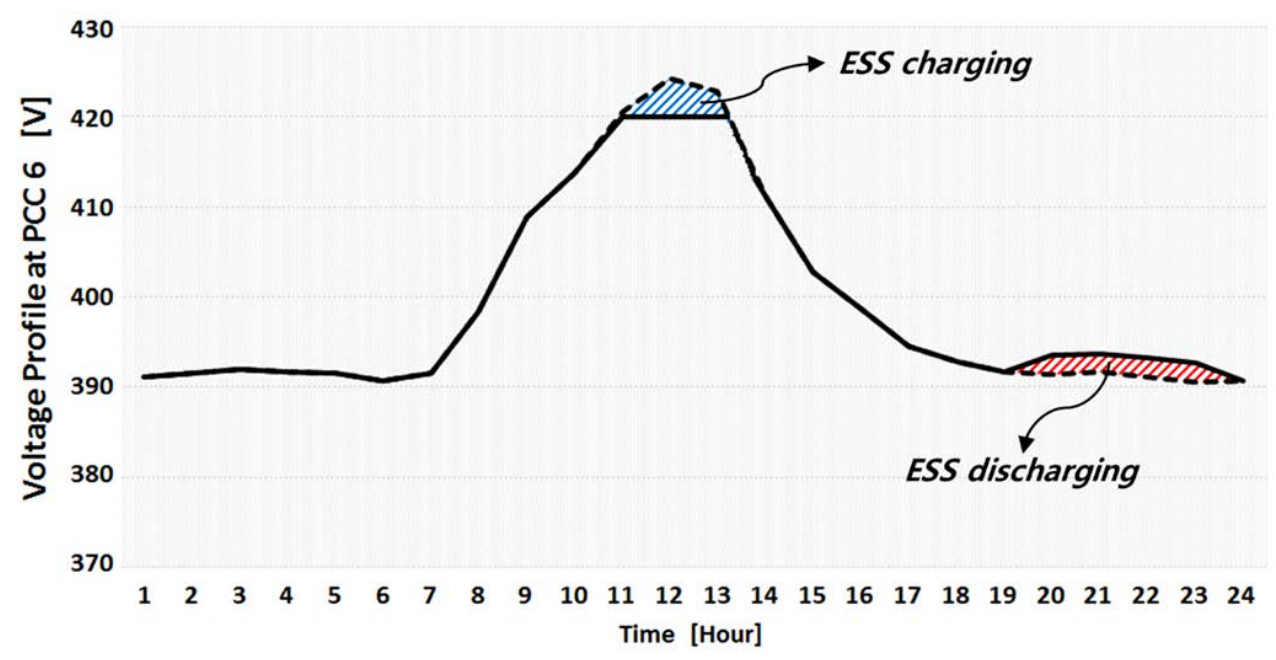

Table 6 summarizes the result when the available ESS power is equally discharged from 7 to $11 \mathrm{pm}$. In this case, it is assumed that this time period corresponds to the time when the load demand is low and DG generation is high. This discharging period must be set before the discharging is performed. In addition, this time period can be varied according to the distribution system load and generation configuration.

Table 6. ESS equally discharging schedule between 7 and $11 \mathrm{pm}$.

\begin{tabular}{ccccccc}
\hline Time & PCC 1 & PCC 2 & PCC 3 & PCC 4 & PCC 5 & PCC 6 \\
\hline 19:00-20:00 & $444 \mathrm{~W}$ & $724 \mathrm{~W}$ & $1063 \mathrm{~W}$ & $1402 \mathrm{~W}$ & $1804 \mathrm{~W}$ & $2213 \mathrm{~W}$ \\
20:00-21:00 & $444 \mathrm{~W}$ & $724 \mathrm{~W}$ & $1063 \mathrm{~W}$ & $1402 \mathrm{~W}$ & $1804 \mathrm{~W}$ & $2213 \mathrm{~W}$ \\
21:00-22:00 & $444 \mathrm{~W}$ & $724 \mathrm{~W}$ & $1063 \mathrm{~W}$ & $1402 \mathrm{~W}$ & $1804 \mathrm{~W}$ & $2213 \mathrm{~W}$ \\
22:00-23:00 & $444 \mathrm{~W}$ & $724 \mathrm{~W}$ & $1063 \mathrm{~W}$ & $1402 \mathrm{~W}$ & $1804 \mathrm{~W}$ & $2213 \mathrm{~W}$ \\
\hline
\end{tabular}

The other algorithm for discharging the power is based on the optimization technique. Through the DC power flow calculation, the distribution line voltage can be estimated. The capacity of discharging power of each ESS can be calculated with the GA method. By setting the voltage lower limit, when the distribution line voltage reaches below the defined lower voltage limit, the complementary optimized discharging capacity of each ESS for voltage regulation is calculated. Table 7 summarizes the result of this optimal discharging algorithm. In addition, this result shows that when the ESS is fully discharged, the discharging operation is complete.

Table 7. ESS optimally discharging schedule for voltage compensation.

\begin{tabular}{ccccccc}
\hline Time & PCC 1 & PCC 2 & PCC 3 & PCC 4 & PCC 5 & PCC 6 \\
\hline 19:00-20:00 & $321 \mathrm{~W}$ & $530 \mathrm{~W}$ & $786 \mathrm{~W}$ & $1042 \mathrm{~W}$ & $1345 \mathrm{~W}$ & $1646 \mathrm{~W}$ \\
20:00-21:00 & $276 \mathrm{~W}$ & $456 \mathrm{~W}$ & $676 \mathrm{~W}$ & $897 \mathrm{~W}$ & $1158 \mathrm{~W}$ & $1417 \mathrm{~W}$ \\
21:00-22:00 & $374 \mathrm{~W}$ & $616 \mathrm{~W}$ & $914 \mathrm{~W}$ & $3667 \mathrm{~W}$ & $4715 \mathrm{~W}$ & $5788 \mathrm{~W}$ \\
22:00-23:00 & $804 \mathrm{~W}$ & $1293 \mathrm{~W}$ & $1876 \mathrm{~W}$ & - & - & - \\
\hline
\end{tabular}




\section{Conclusions}

This paper introduced a voltage regulation concept for low-voltage grids with high PV penetration that use the ESS as the solution. Using a smart metering system, the algorithm presented in this paper performs the complementary operation of all the ESSs installed in a distribution line, and it is not a local control method for individual ESS systems. The power usage/generation data at each PCC is collected from the smart metering system and from these data, the complementary operation scheduling for all the ESSs is performed. Through a PSCAD simulation, it is verified that the derived result of the ESS scheduling is effective for voltage regulation. The required ESS capacity varies according to the system structure. It is expected that the proposed methodology and formulations will be useful for grid planning.

\section{Acknowledgments}

This research was made possible by the support of the KEPCO (Korea Electric Power Corporation) project "Modeling and Analysis of LVDC Distribution Network and Equipment" (No. R12DA01) and by the Human Resources Development Program (No. 20134030200340) of the Korea Institute of Energy Technology Evaluation and Planning (KETEP) grant.

\section{Conflicts of Interest}

The authors declare no conflict of interest.

\section{References}

1. Pourmousavi, S.A.; Cifala, A.S.; Nehrir, M.H. Impact of High Penetration of PV Generation on Frequency and Voltage in a Distributed Feeder. In Proceedings of the North American Power Symposium (NAPS), Champaign, IL, USA, 9-11 September 2012.

2. Kim, T.E.; Kim, J.E. Voltage regulation coordination of distributed generation system in distribution system. Power Eng. Soc. Summer Meet. 2001, 1, 480-484.

3. Choi, J.H.; Kim, J.C. Advanced voltage regulation method of power distribution systems interconnected with dispersed storage and generation systems. IEEE Trans. Power Deliv. 2001, 16, 329-334.

4. Marra, F.; Yang, G.Y.; Traeholt, C.; Larsen, E.; Ostergaard, J.; Blazic, B.; Deprez, W. EV charging facilities and their application in LV feeders with photovoltaics. IEEE Trans. Smart Grid 2013, 4, 1533-1540.

5. Yu, W.; Lie, D.; Huang, Y. Operation optimization based on the power supply and storage capacity of an active distribution network. Energies 2013, 6, 6423-6438.

6. De Oliveira Gomes, A.; Meirelles Gouvea, M. DC Power Flow Optimization with a Parallel Evolutionary Algorithm. In Proceedings of the Transmission and Distribution: Latin America Conference and Exposition (T\&D-LA), Montevideo, Uruguay, 3-5 December 2012.

7. Lu, S.; Zhou, N.; Kumar, N.P.; Samaan, N.; Chakrabarti, B.B. Improved DC Power Flow Method Based on Empirical Knowledge of the System. In Proceedings of the Transmission and Distribution Conference and Exposition, New Orleans, LA, USA, 19-22 April 2010. 
8. Chakraborty, S.; Seniyu, T.; Toyama, H.; Saber, A.Y.; Funabashi, T. Determination methodology for optimizing the energy storage size for power system. Gener. Trans. Distrib. IET 2009, 3, 987-999.

9. Depuru, S.S.S.R.; Wang, L.; Devabhaktuni, V. Smart meters for power grid: Challenges, issues, advantages and status. Renew. Sustain. Energy Rev. 2011, 15, 2736-2742.

10. Birge, B. PSOt-a Particle Swarm Optimization Toolbox for Use with MATLAB. In Proceedings of the 2003 IEEE Swarm Intelligence Symposium, Indianapolis, IN, USA, 24-26 April 2003.

11. Glavin, M.E.; Chan, P.K.W.; Hurley, W.G. Optimization of Autonomous Hybrid Energy Storage System for Photovoltaic Applications. In Proceedings of the Energy Conversion Congress and Exposition, San Jose, CA, USA, 20-24 September 2009.

(C) 2013 by the authors; licensee MDPI, Basel, Switzerland. This article is an open access article distributed under the terms and conditions of the Creative Commons Attribution license (http://creativecommons.org/licenses/by/3.0/). 